\title{
DIE SAW SE ROL IN SWA
}

\begin{abstract}
Apart from the fact that the assistance of the SADF is necessary in many fields in SWA, such as public services and the medical and agricultural fields, it's presence also serves another very important purpose. For as long as the Cubans are present in Angola, the SADF cannot withdraw. The Cubans exercise neo-colonialism in Angola and the moment the SADF withdraws from SWA this will create a void enabling the Cuban Forces to advance towards the South.
\end{abstract}

Vir die Suid-Afrikaner is oorlog geen nuwe ervaring nie. Sedert die vroegste jare al was hy voortdurend in oorlewingstryd gewikkel wat by herhaling op oorlog uitgeloop het. Aanvanklik was daar die botsings met oorlogsugtige swart stamme en daarna die verset teen Britse imperialisme; in hierdie eeu twee wêreldoorloë, die Koreaanse konflik en vandag die bosoorlog - oftewel die verdediging van die landsgrense teen 'n vyand wat die orde, gesag, vrede, stabiliteit en welvaart in Suidwes-Afrika en die Republiek van Suid-Afrika wil vernietig. Hierdie oorlog moet nie geïsoleerd gesien word nie, maar in perspektief geplaas word teen die agtergrond van 'n nog groter konflik, naamlik dié van die wye Westerse demokrasie en die Vrye Wêreld teen die wêreldoorheersingsdrang van die Marxistiese kommunisme. In hierdie stryd wat op baie fronte en met alle beskikbare middele gevoer word, speel die verowering van Suid-Afrika 'n sleutelrol. Om uitvoering te gee aan hierdie strategie, span die kommuniste die revolusionêre bewegings as surrogate in wat vir die sogenaamde bevryding van die subkontinent veg. Hierdie terroristegroepe se uitsluitelike oogmerk is om deur geweld en bloedvergieting die bestaande wettige bestel omver te werp. Hulle ontvang enorme militêre hulp van kommunistiese lande asook ruim finansiële bystand van linksgesinde organisasies in die internasionale gemeenskap, insluitende die VVO, waardeur hulle in staat gestel word om hul veldtog van terreur voort te sit. Die terroriste tree teen die RSA op vanuit hul basisgebiede in naburige Swart state waar die kommuniste alreeds 'n vastrapplek gekry het, in veral Mosambiek en Angola.

Suid-Afrika het in die vroeë sestigerjare die stryd teen hierdie vyand aangeknoop. Dit is veral op die noordelike grense van Suidwes-Afrika waar die Suid-Afrikaanse Veiligheidsmagte die afgelope sestien jaar verbete veg teen terrorisme. Hierdie konflik het ontstaan toe die Marxistiesgeoriënteerde South West Africa People's Organization (SWAPO) in 1962 besluit het om, parallel met die VVO se politieke bemoeiinge vir die onttrekking van Suid-Afrika uit Suidwes-Afrika, 'n militêre aanslag teen die gebied te loods. Die Suid-Afrikaanse Polisie was benewens hul misdaadvoorkomingstaak, indertyd ook verantwoordelik vir die beskerming van die gebiedsgrense. Die situasie in die noorde van SWA was aanvanklik nie op hoë vlak as suiwer militêr geïdentifiseer nie. Derhalwe, en vanweë die politieke implikasies wat dit vir die RSA sou meebring indien hy sy militêre mag aldaar aanwend, het die SAP die teeninsurgensietaak verrig. 'n Aantal lede van die Suid-Afrikaanse Leër was nietemin by hierdie SAP-Teeninsurgensie-eenheid ingedeel om vertroud te raak met operasionele toestande

Die eerste noemenswaardige insident tussen die SAP en die terroriste was die aanval deur ' $n$ klein polisiemag op die terroristeopleidingskamp te Ungulumbashe in Wes-Ovambo op 26 Augustus 1966. Dit het inderwaarheid die Suid-Afrikaanse Veiligheidsmagte se lang en vermoeiende veldtog teen die vyand ingelui. Mettertyd het toenemende terroristebedrywighede voorgekom en was 'n uitbreiding van die voorkomingsaksies en wyer ontplooiing van bewakers op die grens nodig. Die SAP het sy aantal poste in strategiese gebiede vermeerder, spesiale oprukeenhede ontplooi en gereelde patrollies langs die grens ingestel. Terselfdertyd het ook gebeure op die politieke front, naamlik die VVO se besluit in Oktober 1966 om die Republiek te dwing om sy administrasie oor Suidwes-Afrika te beëindig, die militêre weerbaarheid van die gebied van aktuele belang gemaak.

Hieruit het die vestiging van die eerste SAW-eenheid in die noorde van SWA in 1968 voortgevloei, wat deels in die Kavango en deels in die Caprivi ontplooi is. Binne ' $n$ jaar is dit gevolg deur die stiging van verdere eenhede in genoemde gebiede asook in Ovamboland, hoewel slegs nog 'n beperkte aantal Weermagslede betrek is.

Tot op hierdie tydstip het die Suid-Afrikaanse 
Polisie nog daarin geslaag om die insurgensiebedreiging effektief te bekamp. Intussen het die konsentrasie van terroriste op die grens met naburige lande egter toegeneem en as mede die getal wat na Suidwes-Afrika geïnfiltreer het. Hierdeur het die frekwensie van insidente skerp gestyg. Die para-militêre rol van die Polisie het gevolglik veeleisender geword totdat ' $n$ toedrag van sake bereik is waar die situasie 'n suiwer militêre betrokkenheid geverg het. Vanaf April 1973 is die taak van grensverdediging dan ook geleidelik deur die SAW by die Polisie oorgeneem. 'n Beperkte Weermagsontplooiing was voldoende hiervoor maar verhoogde buitelandse hulp aan die terroriste wat hulle in staat gestel het om hul optrede te verskerp, het vanaf 1975 'n drastiese verhoging in die magspeile van die Weermag in die operasionele gebied genoodsaak vir effektiewe beveiliging van die land en sy mense. Huidiglik, op die vooraand van die onafhanklikheid van Suidwes-Afrika, is die SWA Gebiedsmag besig om op sy beurt geleidelik dié verpligting by die SAW oor te neem.

Afgesien van militêre het ook politieke motivering ten grondslag gelê van SA se aanwending van die Veiligheidsmagte in die gebied en hier moet vlugtig verwys word na die mandaat wat in 1920 deur die Volkebond aan Suid-Afrika toegeken is om die gebied te administreer. Die RSA het ' $n$ lang geskiedenis van nougesette nakoming van internasionale verpligtinge. Ten opsigte van SWA is dit van nasionale prestige-belang dat die Suid-Afrikaanse regering onversteurd toegelaat sal word om die mandaatverpligting eerbaar na te kom. Sedert die ontbinding van die Volkebond het die Republiek steeds die standpunt gehuldig dat ofskoon die mandaat oor SWA verval het, hy sou voortgaan om die gebied in die gees daarvan te bestuur. Die RSA se nasionale doelstelling vir SWA is dus om binne die gees van die mandaatakte, die maatskaplike en ekonomiese welvaart van die inwoners van die gebied te bevorder. En dit is die taak van die Suid-Afrikaanse Weermag, as ' $n$ beleidsinstrument van die regering om, wanneer dit aan hom opgedra word, hierdie nasionale prestige-belang te handhaaf en die verwesentlikking van hierdie nasionale doelstelling te beveilig en te bevorder. Dit beteken dat die Weermag SWA moet vrywaar van militêre aksie wat die RSA se bestuur van die mandaat en sy nasionale doelstelling, ten doel het.

Die teenwoordigheid van die SAW in SWA word verder genoodsaak om te midde van onrus en onsekerheid aan die bevolking die nodige seku- riteit en stabiliteit te verskaf. Dat die bevolking besef in watter mate dit die geval is, blyk daaruit dat hulle reeds in 1972 gevra het dat die Weermag sy teenwoordigheid in die gebied moet handhaaf. 'n Spesifieke versoek in hierdie verband is op 2 Mei 1972 deur die destydse hoofraadslid van die Wetgewende Vergadering van Ovambo, kaptein Filemon Elifas, aan die SuidAfrikaanse premier, mnr B.J. Vorster, gerig. Mnr Vorster het hom die versekering gegee (en dit is daarna gereeld deur die Suid-Afrikaanse regering herhaal) dat solank die bevolking die teenwoordigheid van die Veiligheidsmagte in die gebied verlang, hulle daar sou aanbly.

Hoewel dit die Veiligheidsmagte se primêre taak is om die vyand op te spoor en te vernietig, erken die SAW die beginsel dat die stryd in revolusionêre oorlogvoering $80 \%$ polities en $20 \%$ militêr van aard is. Uit die aard van die saak was die aanvanklike fase teen die vyand hoofsaaklik militêr gerig, maar mettertyd is bogenoemde konsep in die oorlog geïmplementeer sodat die Veiligheidsmagte daagliks op 'n verskeidenheid terreine wat onderwys, landbou, medies, ingenieurswese en administrasie insluit, 'n essensiële bydrae lewer ook tot die sosio-ekonomiese ontwikkeling en welvaart van die gebied se inwoners

Wat nie uit die oog verloor mag word nie, is die feit dat die rol wat militêre personeel ook op niemilitêre gebied speel, van uiterste en selfs deurslaggewende belang is. Die sin en betekenis hiervan word ten beste begryp indien kennis geneem word van die uitslag van die oorlog in Viëtnam.

Strateë en politieke waarnemers het ná die oorlog in Viëtnam tot die gevolgtrekking geraak dat die Amerikaanse magte dié jarelange stryd vir die duur van hul teenwoordigheid in SuidoosAsië wel militêr gesproke gewen het. Die VSA het die oorlog egter op ander terreine van die oorlogspektrum verloor. In dié verband is die negatiewe en ongemotiveerde gesindheid van die Amerikaanse volk en die inwoners van Suid-Viëtnam as die hoofoorsake aangedui. Die belangrikste les wat hieruit geleer kan word, is naamlik dat die Amerikaanse magte in Suid-Viëtnam te veel op die militêre aspekte van oorlog gekonsentreer het en hul pligte ten opsigte van die voorligting en morele onderskraging van die inheemse bevolking skromelik versaak het.

In hierdie opsig speel die SA magte en lede van die SWA Gebiedsmag reeds 'n dinamiese rol in 


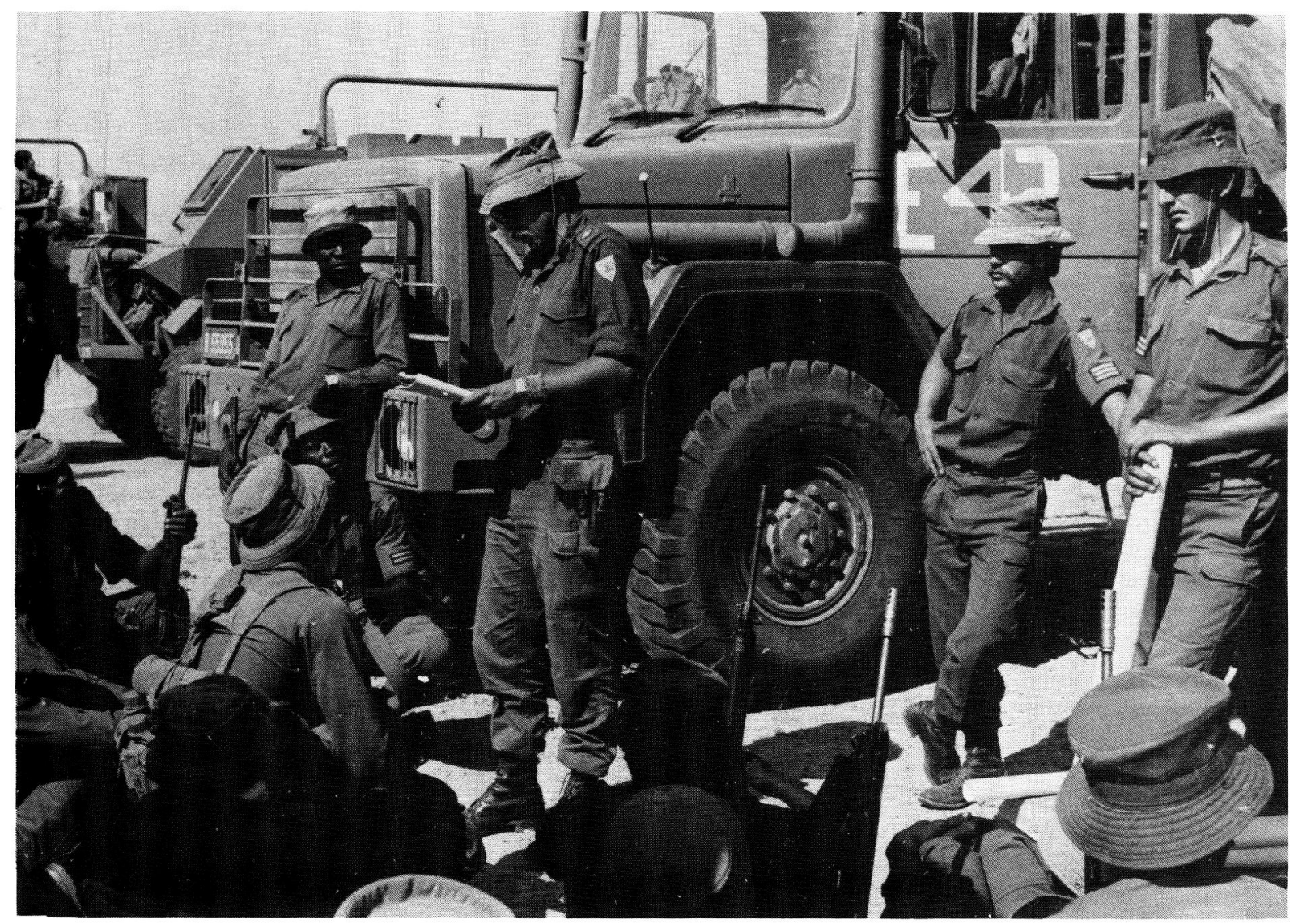

Lede van die Suid-Afrikaanse Veiligheidsmagte in SWA word tydens 'n operasie teen die militêre vleuel van SWAPO voorgelig - 'n blik op 20 persent van die stryd teen terrorisme.

die sosio-ekonomiese lewe van SWA. Militêre personeel is byvoorbeeld ten nouste betrokke by die lewering van gemeenskapsdienste.

\section{Gemeenskapsdienste}

Die indruk kan maklik geskep word dat SuidAfrika se militêre betrokkenheid in SWA uitsluitlik sentreer om die langdurige gewapende konflik met SWAPO se militêre vleuel. Die SAW se teenwoordigheid in SWA behels egter veel meer as die blote beveiliging van die gebied. Die SAW se rol in die algemene ontwikkeling van SWA, wat vir onafhanklikheid bestem is, blyk duidelik uit die vooruitgang wat op die mediese terrein en die gebied van die onderwys en die landbou behaal is.

Op die gebied van onderwys het statistieke getoon dat die SAW se invloed in, SWA 'n toename in die hoeveelheid skole tot gevolg gehad het. In Ovambo het die getal skole tussen 1962 en 1982 met 281 toegeneem. In Kavango was daar $4 \dot{6}$ skole in 1962 en tien jaar later het dit na 28 toegeneem. Twee jaar gelede, het die aantal skole reeds op 265 gestaan. Binne twintig jaar het die getal skole met 219 toegeneem. Die leerlinggetalle het ook drasties verhoog sedert die SAW se teenwoordigheid. In Ovambo alleen het die getal leerlinge sedert 1962 tot twee jaar gelede met 101399 gestyg. In Kavango en OosCaprivi was die toename net so geweldig. In Kavango het die getalle binne tien jaar (1962-1972) met 9533 gestyg. In 1982 het statistieke getoon dat die leerlinggetalle 29611 was. In Oos-Caprivi het die getalle tussen 1962 en 1982 gestyg van 1503 na 14036 . Die toename in onderwysers was getalswys eweneens hoog. In Ovambo was daar in 1962 sowat 672 onderwysers teenoor die 3060 van twee jaar gelede. In Kavango het die onderwysersgetalle binne tien jaar (1962-1972) met 886 toegeneem. Die aantal onderwysers in Oos-Caprivi het al om die tien jaar meer as verdubbel, en in 1972 was daar reeds 190 onderwysers teenoor die 42 van 1962. Die statistieke van 2 jaar gelede wys dat daar in 1982 reeds 751 onderwysers was.

\section{Landbou}

Om die inheemse bevolking beter op te lei in grondbewerking, bemesting, verbetering van 


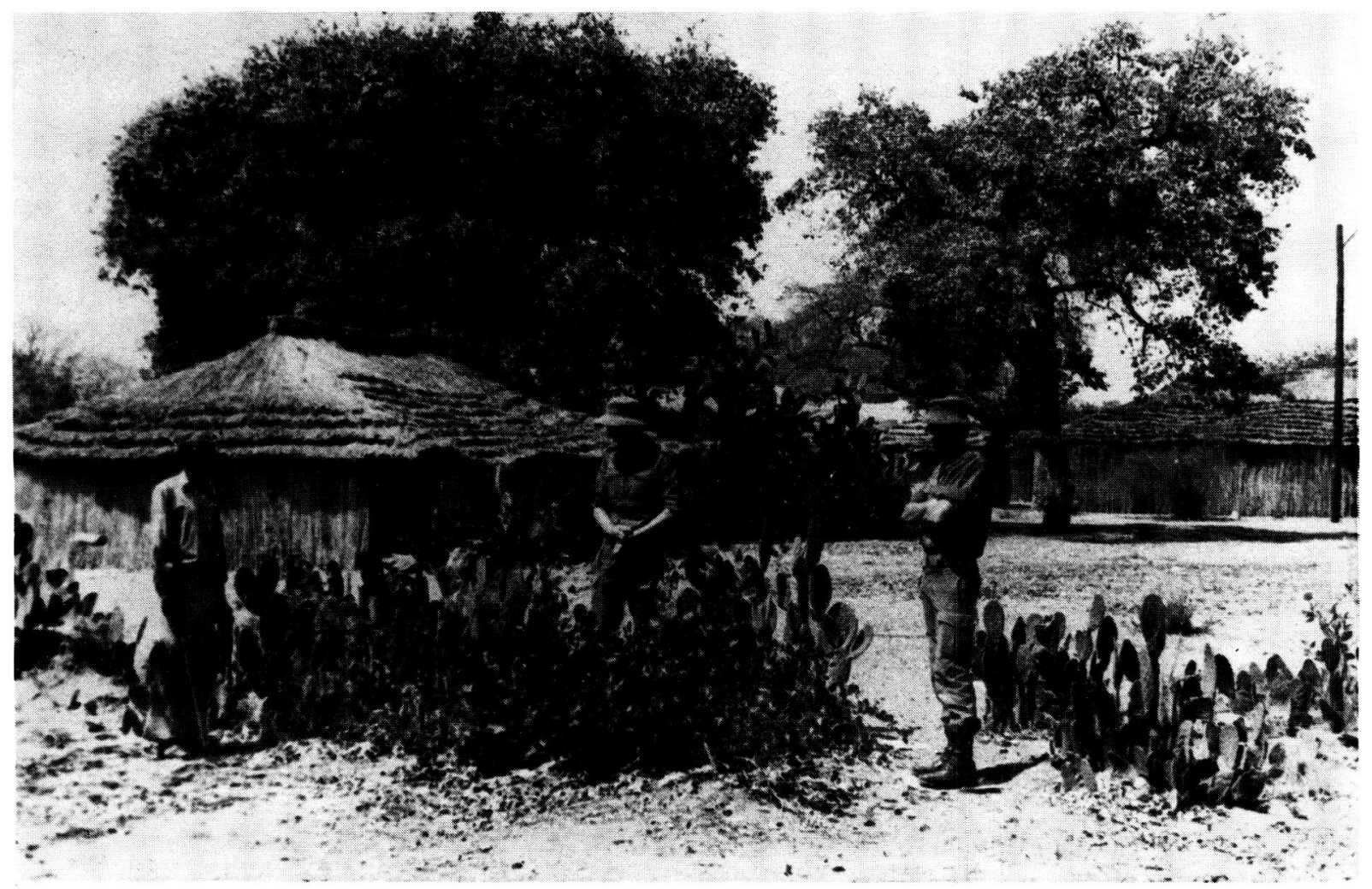

In hierdie ruim hutte in die vakansiekamp Maria Mwengere gaan die kinders tuis. Die kamp het genoeg akkommodasie vir tussen 400 en 500 kinders.

veestapels en bestryding van peste, plae ens het die SAW, dienspligtiges voorsien. Hulle is hoofsaaklik veeartse, voorligters en tegnici. Om die nodige inligting oor te dra is landboukolleges by Ogongo (Ovamboland) en Mashare (Kavango) opgerig. By Kapako (Kavango) is ook 'n opleidingsentrum waar voornemende boere opgelei word in die tegnieke van aanplanting, bemesting en besproeiing van groente. Lede van die plaaslike bevolking wat in boerdery belangstel, kry ook van die Kaisosi-projek 'n stuk grond van 1 hekt.

\section{Medies}

In die operasionele gebied is al die tandartse, dokt'ers en sielkundiges aan die SAW verbonde. In 1960 was daar slegs 1 geneesheer in Kaokoland, 4 in Ovamboland en 2 in Kavango. Op 25 April 1983 was daar 49 militêre geneeshere en 9 nie-militêre dokters in sektor 10. (Ovamboland en Kaokoland). Dit kom neer op 'n toename van 1060\% binne 23 jaar. In die ooreenstemmende tydperk het die geneeshere in Kavango met $650 \%$ toegeneem. As die hele sektor 20 (insluitende Wes-Caprivi en Kavango) in berekening gebring word was daar op 1 Junie 1983, 19 geneeshere. In Oos-Caprivi was daar op die-

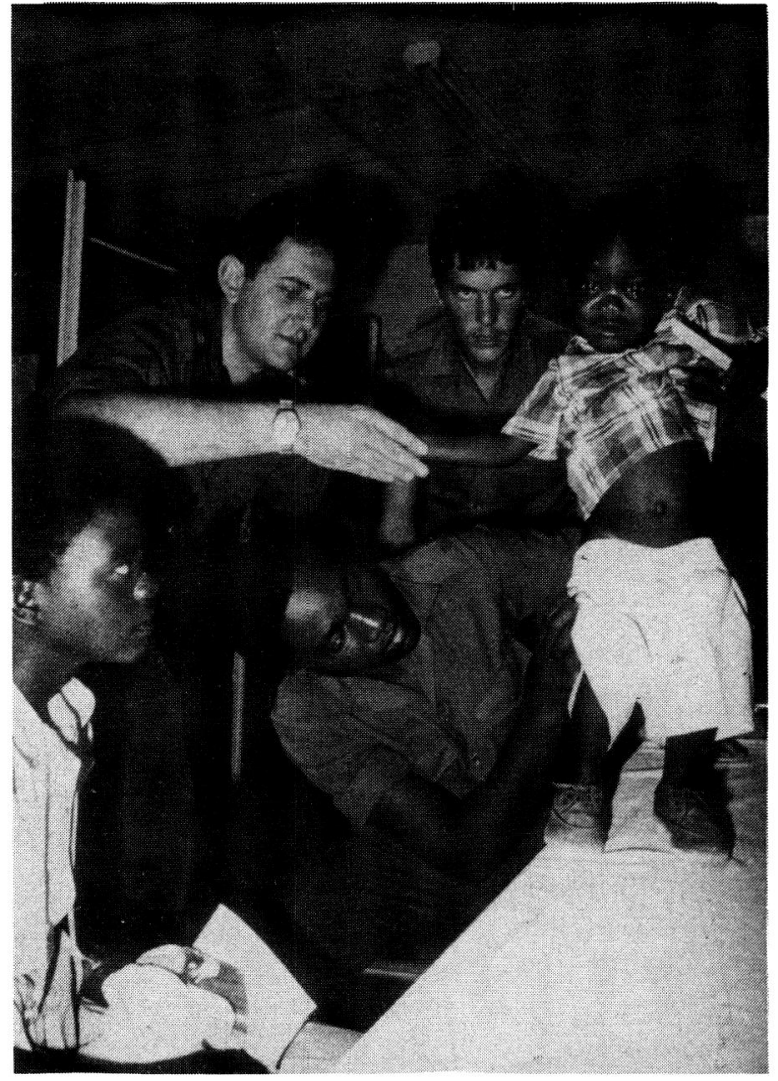

Lede van die SAGD is hler besig om 'n baba van die plaaslike bevolking te ondersoek. 
selfde datum, 8 geneeshere. Indien daar in ag geneem word dat daar in 1960 net een staatsgeneesheer was, word die toename oor die afgelope 23 jaar as $700 \%$ beskou.

\section{Ander terreine}

Die SAW lewer ook diens op ander gebiede, so onder andere op administratiewe gebied, waar departemente ' $n$ tekort aan mannekrag ondervind. Opleiding van die plaaslike bevolking geskied terselfdertyd. Die SAW staan die Regering van Kavango ook by met natuurbewaring deur dienspligtiges na die Mwengere-jeugkamp te stuur om by leerlinge ' $n$ liefde vir plante en diere te kweek. Dienspligtiges het ook gehelp om die saagmeule by Lutala (Caprivi) op te rig. Die SA Leër se gesondheidsinspekteurs doen ook gereeld inspeksie by verskillende instansies waar daar met voedsel gewerk word. Die SAW lewer ook nooddienste. Kos word verskaf wanneer nodig, so ook reddingspogings in oorstroomde gebiede.

Afgesien van die feit dat die SAW se hulp noodsaaklik is in SWA, dien sy teenwoordigheid ook nog ' $n$ ander doel. Solank as wat die Kubane in Angola teenwoordig is, kan die SAW nie onttrek nie. Die Kubane bedryf neo-kolonialisme in Angola en sodra die SAW hom onttrek uit SWA, sal dit 'n leemte skep en die Kubaanse magte sal nie huiwer om suidwaarts op te ruk nie. 